Article

\title{
Experimental Study on Coherent Structures by Particles Suspended in Half-Zone Thermocapillary Liquid Bridges: Review
}

\author{
Ichiro Ueno (D)
}

Citation: Ueno, I. Experimental Study on Coherent Structures by Particles Suspended in Half-Zone Thermocapillary Liquid Bridges: Review. Fluids 2021, 6, 105. https:// doi.org/10.3390/fluids6030105

Academic Editor: Marcello Lappa

Received: 26 January 2021

Accepted: 22 February 2021

Published: 4 March 2021

Publisher's Note: MDPI stays neutral with regard to jurisdictional claims in published maps and institutional affiliations.

Copyright: (C) 2021 by the author. Licensee MDPI, Basel, Switzerland. This article is an open access article distributed under the terms and conditions of the Creative Commons Attribution (CC BY) license (https:// creativecommons.org/licenses/by/ $4.0 /)$.
Department of Mechanical Engineering, Faculty of Science \& Technology, Tokyo University of Science, Chiba 278-8510, Japan; ich@rs.tus.ac.jp

\begin{abstract}
Coherent structures by the particles suspended in the half-zone thermocapillary liquid bridges via experimental approaches are introduced. General knowledge on the particle accumulation structures (PAS) is described, and then the spatial-temporal behaviours of the particles forming the PAS are illustrated with the results of the two- and three-dimensional particle tracking. Variations of the coherent structures as functions of the intensity of the thermocapillary effect and the particle size are introduced by focusing on the PAS of the azimuthal wave number $m=3$. Correlation between the particle behaviour and the ordered flow structures known as the Kolmogorov-Arnold-Moser tori is discussed. Recent works on the PAS of $m=1$ are briefly introduced.
\end{abstract}

Keywords: thermocapillary-driven convection; half-zone liquid bridges; particles; coherent structures; particle accumulation structure (PAS); high Prandtl number fluids

\section{Introduction}

Coherent structures by suspended particles were first found in thermocapillary halfzone liquid bridges by Schwabe et al. [1]. In the geometry of a "half-zone liquid bridge," a liquid is bridged between the coaxial face-to-face disks by its surface tension, and each disk is kept at a constant but different temperature to impose a non-uniform temperature distribution over the free surface of the liquid bridge. One defines the intensity of the thermocapillary effect by the Reynolds number $\operatorname{Re}=\left|\gamma_{T}\right| \Delta T L /\left(\rho v^{2}\right)$, where $\gamma_{T}$ is the temperature coefficient of surface tension $\gamma, L$ is the characteristic length of the system, $\rho$ and $v$ are the density and the dynamic viscosity of the test liquid, respectively. The temperature difference between the end disks, $\Delta T$, is the governing factor to vary the thermocapillary effect. The intensity is also generally described as the Marangoni number $\mathrm{Ma}=\left|\gamma_{T}\right| \Delta T L /(\rho \nu \kappa)=\operatorname{RePr}$, where $\kappa$ is the thermal diffusivity of the test liquid, and $\operatorname{Pr}=v / \kappa$ indicates the Prandtl number. Schwabe et al. [1] found such unique phenomenon in the traveling-wave-type oscillatory convections in the liquid bridges of high Pr fluids, and named this as the particle accumulation structure (PAS). In the geometry concerned, the thermocapillary-driven convection exhibits a transition from the two-dimensional timeindependent ("steady") convection to the three-dimensional time-dependent ("oscillatory") one [2-5] by so-called hydrothermal-wave instability [6]. There exist two types of oscillatory convection [4,5] before the secondary instability [7]: the standing-wave-type oscillation and the travelling-wave-type oscillation. In the former, one finds a pair of thermal waves propagating over the free surface with the same amplitude and the same propagation speed but in the opposite azimuthal directions. In the latter, on the other hand, one finds a single thermal wave propagating in an azimuthal direction. The PAS is formed in the travelling-wave-type oscillatory convection [1,8,9]. After the onset of the hydrothermalwave instability, the oscillatory convection emerges in the liquid bridge accompanied by an azimuthal wave number $m$, depending on the liquid bridge shapes defined as the aspect ratio $\Gamma=H / R[2,3,5]$ and the volume ratio $V / V_{0}=V /\left(\pi R^{2} H\right)[10]$, where $H$ and $R$ are 
the distances between the disks (or, the height of the liquid bridge) and the disk radius, respectively, and $V$ is the volume of the liquid bridge. Here $V_{0}$ indicates the volume of a straight cylinder, of which the end disks correspond to the end surfaces. The PAS has the same azimuthal wave number as the oscillatory convection by the hydrothermal-wave instability $[8,9,11-14]$. Such characteristics were also well reproduced by the numerical simulations for the PAS of $m=3$ [15-20].

Tanaka et al. [8] indicated via terrestrial experiments that there exist two-types of PAS of the same $m$ by varying the intensity of the thermocapillary effect; spiral loops 1 (SL1) and 2 (SL2). Typical examples of those are illustrated in Figure 1 for the PAS of $m=3$. These are the snapshots observed through the transparent top rod; the white dots correspond to the particles suspended in the liquid bridge. The black circle at the centre is an outlet of the channel drilled through the bottom rod for a liquid supply. The PAS consists of the major structure called the "blade" [8]: When one observes the PAS from above in the laboratory frame, it seems to be rotating without changing its shape as the rigid structure. The azimuthal direction of the rotation of the PAS is the same as that of the thermal wave over the free surface. The number of the blades matches to the azimuthal wave number $m$ of the oscillatory convection after the onset of the primal instability. The tip of the blades corresponds to the trajectory of the particles travelling near the free surface toward the cold end from the hot end in the case of $\gamma_{T}<0$. After the travel near the free surface, the particles then penetrate into the central region of the liquid bridge, and rise toward the hot end by following the return flow. The particles change their direction toward the free surface near the hot end to form the tip of the adjacent blade. The net azimuthal direction of the particles forming the PAS is opposite to that of the PAS. The SL1-PAS is the basic structure; if one follows the radial position of the blade $(r)$ by varying the azimuthal position $(\theta)$, one obtains $\partial r / \partial \theta>0$ from the central region toward the tip, and $\partial r / \partial \theta<0$ from the tip toward the central region. The SL2-PAS exhibits an additional loop structure near the tip; when the particles forming the PAS travel near the free surface, they exhibit a sharp additional rotation near the free surface before penetrating into the central region of the liquid bridge. Existing research has dealt mainly with the SL1-PAS, because this type of PAS emerges at lower Ma than that for the SL2-PAS $[8,9,11]$. That means one has to add larger $\Delta T$ to realize the SL2-PAS, which induces a severe and inevitable problem for carrying out the experiments under the normal gravity condition; that is, the evaporation of the test liquid. When one conducts terrestrial experiments, one has to prepare the liquid bridge with a characteristic length $L$ is small enough in order to prevent the deformation of the liquid bridge due to the static pressure [21]. In order to realize high Re for small $L$, however, a large $\Delta T$ must be imposed between the both ends of the liquid bridge. This might be one of the critical reasons why the amount of research on the SL2-PAS has been limited compared to those on the SL1-PAS. One can find some research via numerical simulation on SL2-PAS [20].

In this article, the author introduces the experimental results accumulated in terrestrial environments, which lead to future microgravity experiments on the International Space Station (ISS) by the project "Japanese European Research Experiments on Marangoni Instability (JEREMI)" [22,23]. 

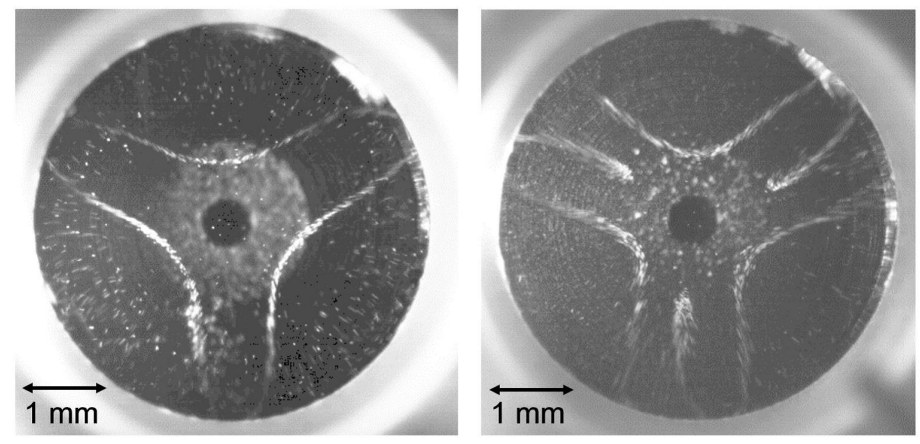

$<$ TOP VIEW >

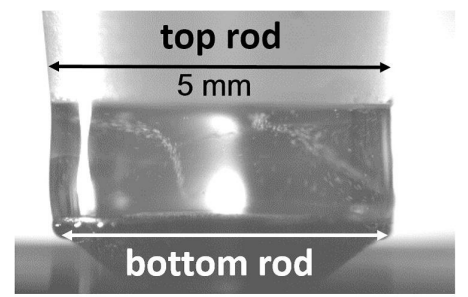

(a)

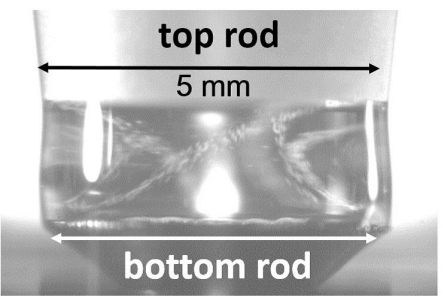

(b)

Figure 1. Snapshots of particle accumulation as viewed from above (top row) and from the side (bottom row) in a liquid bridge of $\operatorname{Pr}=28.6, \Gamma=0.68(R=2.5 \mathrm{~mm})$, and $V / V_{0}=1.0$ : (a) spiral loop (SL)1-particle accumulation structures (PAS) under Ma $=4.7 \times 10^{4}$ and (b) SL2-PAS under $\mathrm{Ma}=5.8 \times 10^{4}$. The direction of the PAS rotation or the travelling-wave-type oscillatory convection by the hydrothermal wave instability is counterclockwise for both cases in the top row, and is from right to left in the bottom row. Note that Ma is evaluated by applying $H$ for the characteristic length L. (Figure 2 in Toyama et al. [11]).

\section{Materials and Methods}

The geometry of the interests is quite simple as aforementioned; one prepares a set of cylindrical disks placed face-to-face with a designated distance between the both end surfaces. There exist a fair amount of research dealing with the half-zone liquid bridges [2,5,24-38]. Note that the transparent rod enables one to observe the particles' behaviours through it. Such a technique was introduced by Hirata et al. [29,30], and has been widely spread to the various research groups. Here an example of the experimental set up is introduced in Figure 2 according to Gotoda et al. [13]. A liquid is sustained between the top rod made of sapphire and the bottom one made of aluminium. End surfaces of the both rods are finished to have the same radius $R$. The top rod is heated by the electric heater winding the rod. The temperature of the rod is measured by the thermocouple, and is controlled by the PID controller. The bottom rod is connected to the base block with the drilled channels. The block is cooled by the flow of coolant pumped from the constant temperature bath. In order to suppress undesignated natural convection around the liquid bridge, an external shield is often installed coaxially to the liquid bridge. An infrared (IR) camera is commonly used to measure the surface temperature. One might have to prepare a tiny window for the IR camera installed on the external shield. The particles' behaviours are observed by camera(s). If one has two cameras, simultaneous observation is possible through the top rod for the top view and through the external shield for the side view. Oba et al. [14] applied three-dimensional particle tracking velocimetry (3-D PTV) with a conventional algorithm; a cubic beam splitter was installed above the top rod in order to realize simultaneous observation via multiple cameras with a different incident angle to the central axis of the liquid bridge through the top rod. It is noted that the characteristic time for the oscillatory convection becomes shorter as the characteristic length becomes smaller; thus high-speed camera(s) might have to be installed for precise observations. 
A variety of test liquids have been employed as high Pr fluids. Silicone oil has been widely used as in Chun and Wuest [24] because of its transparency for visible light and well-known thermal properties including surface tension that exhibits almost linear variation against temperature. Due to the high temperature needed in order to realize thermocapillary-driven convection under high $\mathrm{Ma}$, evaporation of the test liquid becomes a common and severe problem to conducting the experiment as aforementioned. A liquid supply system through the rod has been installed in order to keep $V / V_{0}$ constant $[13,14,39-41]$. One finds apparatus with a similar mechanism used for microgravity experiments $[9,42-44]$.

The existing research has dealt with high Pr fluids in a range of $1 \lesssim \operatorname{Pr} \lesssim 200$. In the following, the effect of Pr on the coherent structures and the thermal flow field will be introduced, especially in the cases of $\operatorname{Pr} \lesssim 30$. Microgravity experiments [21,43-50] dealt with higher Pr than those in terrestrial experiments thus far. Further research is indispensable to discussing the Pr effect on the coherent structures and the oscillatory convection induced by the hydrothermal wave instability in the case of $\operatorname{Pr}>100$.

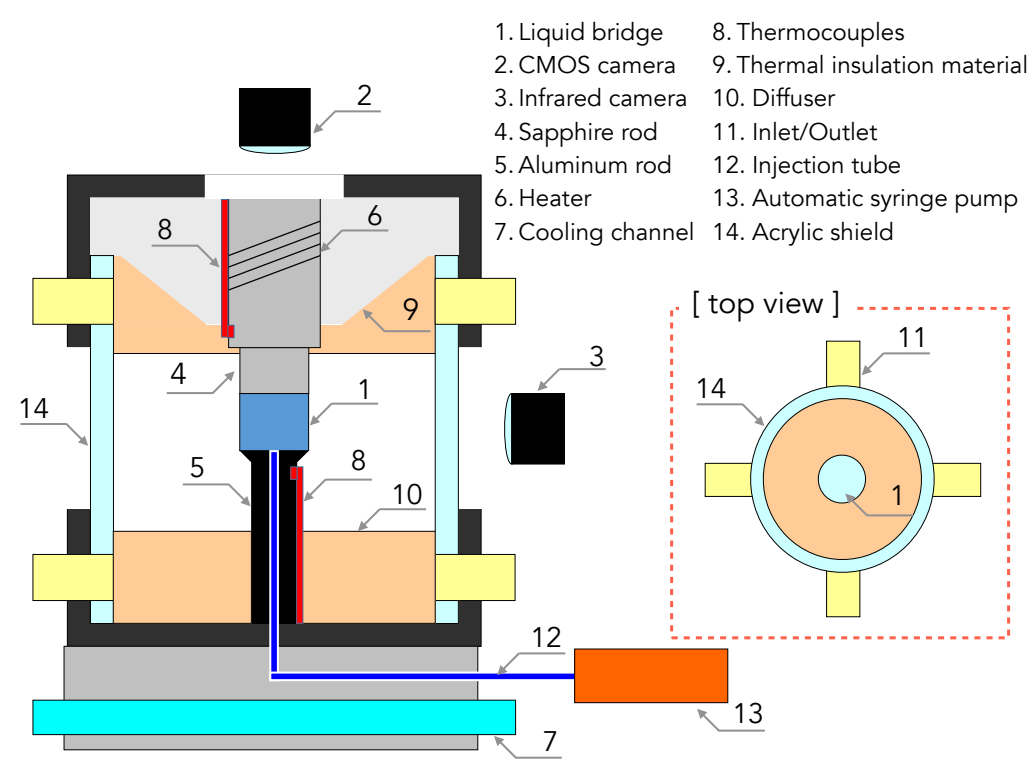

Figure 2. Cross-sectional view of the experimental apparatus (not to scale). The liquid bridge is heated from above in this configuration. A narrow $\mathrm{ZnSe}$ window is placed at a portion of the external shield for the infrared camera to detect the surface temperature through the shield. The CMOS camera for the side view and the displacement sensor are omitted. (Figure 3 in Gotoda et al. [13]).

\section{Thermocapillary-Driven Convection and Coherent Structures}

\subsection{General View}

The physical mechanism for particle accumulation has been discussed over a decade; three major models have been proposed so far. At the early stage after the PAS discovery, Schwabe et al. [9] proposed that the particles were gathered near the free surface due to the Marangoni effect. Through fine experimental observation by using the liquid of $\operatorname{Pr}=15$, they found that the tip of the PAS blade is located on the colder region of the thermal wave over the free surface. They considered that there exists thermocapillary-driven flow toward the colder region due to the negative temperature coefficient of the surface tension, which drives the particles approaching the free surface toward the low-temperature band. When the particles return to the internal region of the liquid bridge, they follow a narrow band of the stream lines to form the PAS. It was indicated, however, that such spatial correlation between the PAS tip and the relatively cold band over the free surface is not always realized; Toyama et al. [11] illustrated the spatial correlations between the SL1- and SL2-PASs and the thermal wave over the free surface (see Figure 3). They conducted a simultaneous observation of the surface temperature from the side and the particle motion inside the 
liquid bridge of $\operatorname{Pr}=28.6$ through the top rod, and reconstructed those distributions in the rotating frame of reference. It was indicated that the tip of the PAS blade locates between the cold and hot bands in the liquid bridge of higher Pr than that in Schwabe et al. [9]. This experimental work revealed that the particles are not collected by the thermocapillary effect over the free surface.

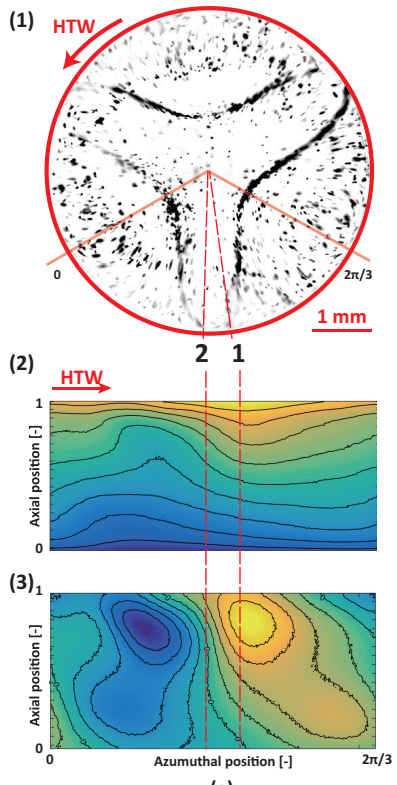

(a)

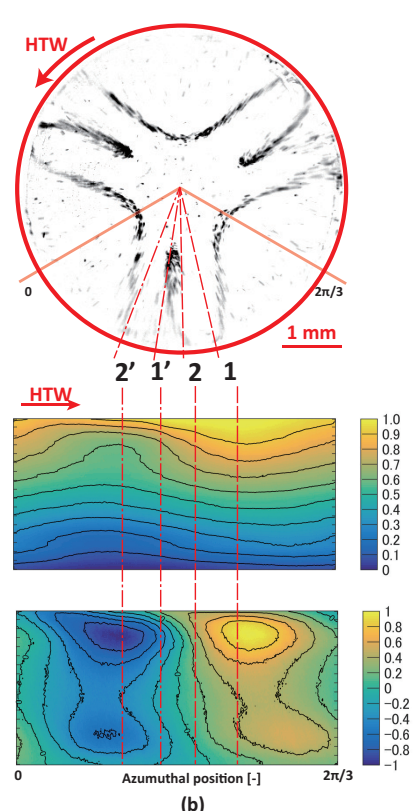

(b)

Figure 3. Correlation between PAS and surface temperatures for (a) SL1-PAS under Ma $=4.7 \times 10^{4}$ and (b) SL2-PAS under Ma $=5.8 \times 10^{4}$ in a liquid bridge of $\operatorname{Pr}=28.6, \Gamma=0.68(R=2.5 \mathrm{~mm})$, and $V / V_{0}=1.0$ (the same condition as shown in Figure 1): Row (1) illustrates the top views of the PASs, and rows (2) and (3) the absolute temperature and the temperature deviation over the free surface in a range of $0 \leq \theta \leq 2 \pi / 3$ (as defined in row (1)), respectively. Ma is evaluated by applying $H$ for the characteristic length $L$. (Figure 11 in Toyama et al. [11]).

Two other models are called the (i) "phase locking model" [51] and (ii) "particle-freesurface interaction model" [17,52]. Pushkin et al. [51] proposed a model based on the "phase locking" between the flow field and the particle motion; they suggested that a PAS would be formed by "synchronization" between the particle turnover motion due to the basic flow in the liquid bridge and the azimuthal convective motion due to the hydrothermalwave instability. Hofmann and Kuhlmann [17] proposed a model by considering densitymatched particles: the PAS would be formed through the transfer of particles that "collide" with the free surface to specific streamlines. They illustrated the presence of closed stream tubes in the flow in the rotating frame, and that particles accumulate on these stream tubes. It was considered that an effect of the finite particle size would force transfers of the particle from one streamline to another. After the proposals of these models, there has been active discussion in this decade [20,39,53-57]. It is indispensable and of great importance to accumulate comprehensive knowledge from experimental and numerical approaches with fine spatial-temporal resolution to lead comprehensive understandings of the PAS formation.

When one pays attention to the formation process of the PAS, especially in order to evaluate the formation time [8,9], we have to measure the accumulation; how much the accumulation is realized. Some measures have been introduced such as "contrast" [41] and "K(t) parameter" [58]. It was indicated that the formation time of SL1-PAS of $m=3$ is of the order of the thermal diffusion time in terrestrial experiments [59]. It must be noted, however, that it is rather impossible in the experiments to disperse the particles without disturbing the thermal-flow field in the liquid bridge $[59,60]$ to evaluate the time it takes 
for the particles to form the PAS. We need supportive data from fine numerical simulation precisely solving the particles' behaviour even close to the free surface and walls [57].

In the following, knowledge on the PAS in fully developed states is introduced.

\subsection{Particle Path Lines to Form Coherent Structures}

\subsubsection{Path Lines}

The PAS seems to rotate azimuthally without changing its shape as a rigid structure at a constant angular velocity in the laboratory frame [8], as aforementioned. When one observes the PAS in the rotating frame of reference, the particles exhibit a coherent structure inside the liquid bridge $[13,14,61]$. Figure 4 illustrates the typical examples of the path lines of the particles forming (a) a triangle zone of the particle depletion and (b) the SL1PAS observed from above (i) in the rotating frame of reference and (ii) in the laboratory frame [13]. The images are obtained by accumulating the snapshots for $7 \mathrm{~s}$ or 10 periods. When one observes the particles in the liquid bridge in the laboratory frame (column (ii)), the particles almost scatter inside the liquid bridge except for the particle depletion zone. At an appropriate $\Delta T$, the particles gather along closed orbits to form coherent structures in the frame of reference rotating with the traveling-wave-type oscillatory convection due to the hydrothermal-wave instability ((b) in column (i)). Mukin and Kuhlmann [55] indicated that the PAS emerges after the particle transfer from the chaotic streamlines to other streamlines located inside of Kolmogorov-Arnold-Moser (KAM) tori, and that such particle transfer is realized by the interaction with the free surface. These KAM tori are three-dimensional closed stream tubes in the liquid bridge, and the spatial structures of the particle accumulations match well to those of the KAM tori such as $\mathrm{T}_{3}^{3}, \mathrm{~T}_{3}^{9}$, and $\mathrm{T}_{\text {core }}$ [61].

(a)

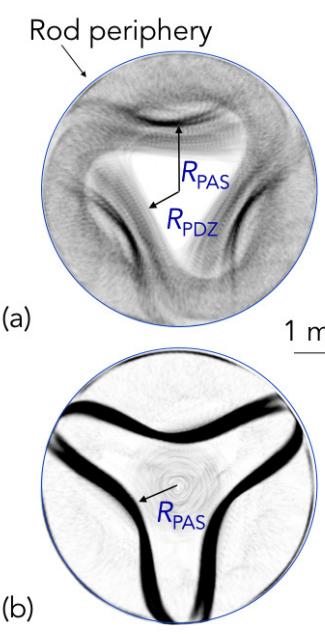

(i)

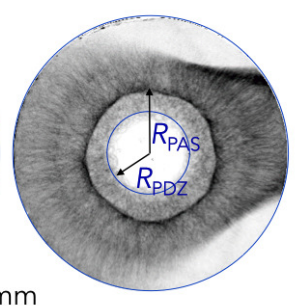

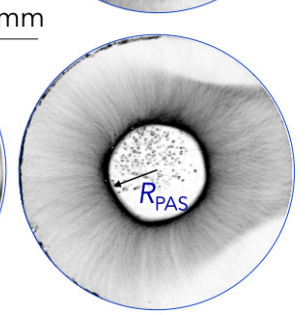

(ii)

Figure 4. Top views of path lines of particles of $15 \mu \mathrm{m}$ in diameter (a) before and (b) after PAS formation in (i) the rotating frame of reference and in (ii) teh laboratory frame by averaging over $7 \mathrm{~s}$ (10 times fundamental periods of hydrothermal wave (HTW)) in a liquid bridge of $\mathrm{Pr}=28.6$, $\Gamma=0.64(R=2.5 \mathrm{~mm})$, and $V / V_{0}=1.0:(\mathbf{a}) \mathrm{Ma}=3.13 \times 10^{4}$ and $(\mathbf{b}) \mathrm{Ma}=4.30 \times 10^{4}$. Note that white regions at the top and bottom right in the images in the column (ii) are the regions where the light from the light source never irradiates in the liquid bridge: the light is supplied to the liquid bridge through the free surface from the left in these images, and one cannot avoid the refraction of the light due to the curvature of the free surface. Those regions become vague and are not apparent by integrating images for a long period in the rotating frame of reference as shown in the column (i). Ma is evaluated by applying $H$ for the characteristic length $L$. (Figure 6 in Gotoda et al. [13]).

\subsubsection{Pattern Map}

The particle accumulation depends on the intensity of the thermocapillary effect; the occurring condition is described as a function of Ma $[9,11]$. Figure 5 illustrates a typical example of the variation of the particle distribution in the rotating frame of reference 
for the particles of different sizes [13]. One notices the formation, the development, and the decay of the coherent structures as Ma varies. After the formation of the coherent structures, the width of the PAS varies as a function of Ma; such variation can be seen for the KAM tori predicted by employing the modelled convection field [58]. Note that, even under the same $\mathrm{Ma}$, the shape of the coherent structure depends on the particle size or corresponding Stokes number $\mathrm{St}=\varrho d_{\mathrm{p}}^{2} /\left(18 H^{2}\right)$ [17], where $\varrho$ is the density ratio between the particle $\rho_{\mathrm{p}}$ and the test fluid $\rho_{\mathrm{f}}$ or $\varrho=\rho_{\mathrm{p}} / \rho_{\mathrm{f}}$, and $d_{\mathrm{p}}$ is the particle diameter. In the present study, the value of $S t$ is of the order of $10^{-5}$. Dependence of the coherent structure on St were examined via numerical simulation by considering a modeled traveling flow in the straight liquid bridge [58]. It has been indicated that the spatial structure of the particle accumulation is defined by the combination of the turnover motion in the $r-z$ plane and the azimuthal motion $[8,60,62]$. In the following, individual particle behaviour is focused upon.

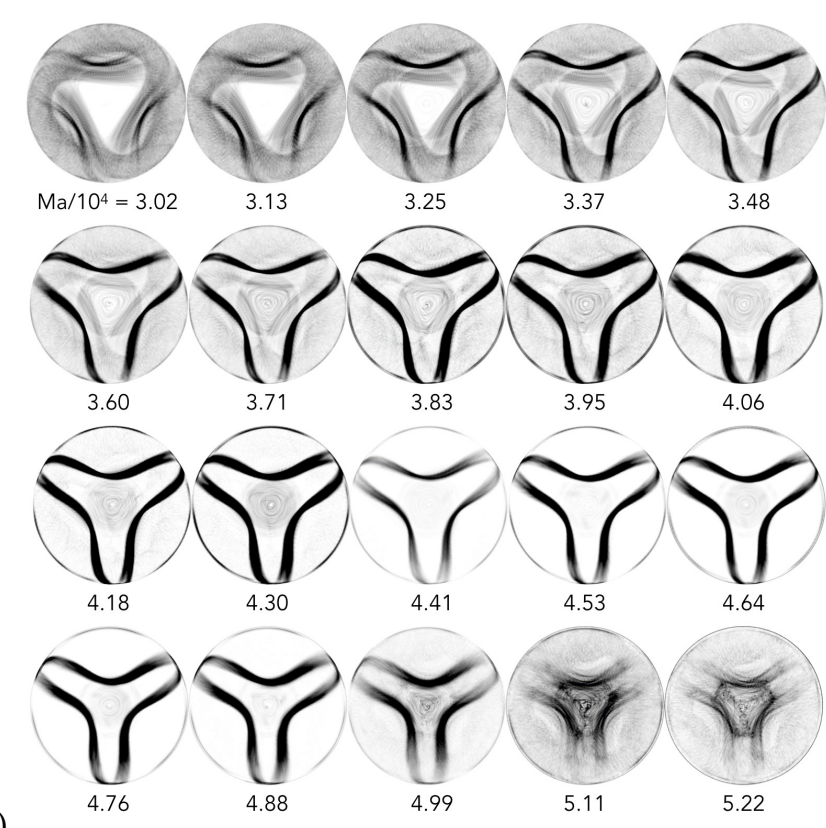

(a)

(b)

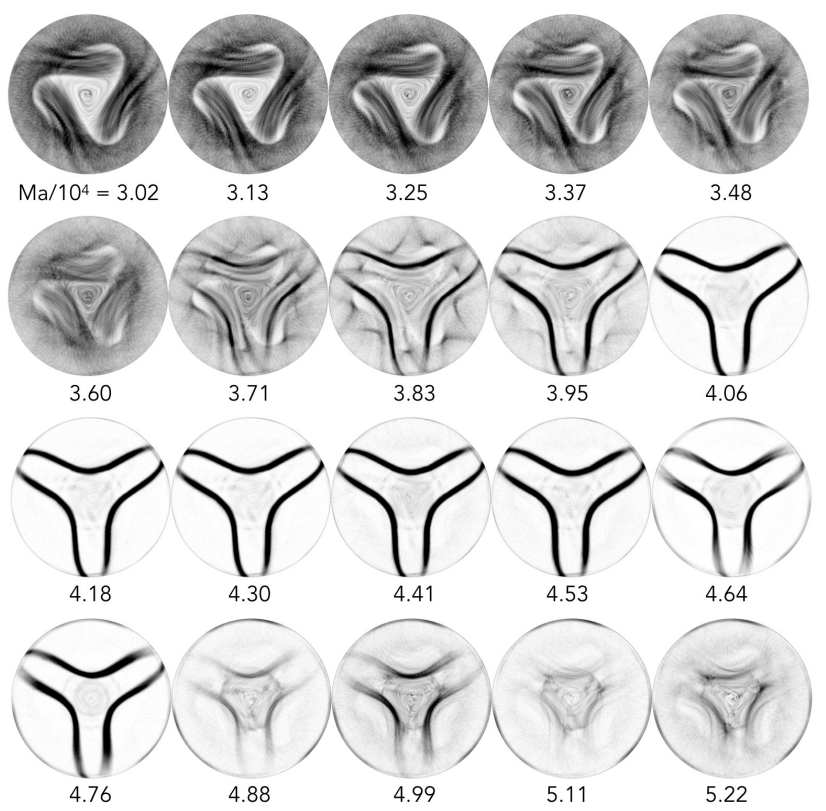

Figure 5. Variations of coherent structures by the particles as a function of Ma for (a) $d_{\mathrm{p}}=15 \mu \mathrm{m}$ and (b) $d_{\mathrm{p}}=30 \mu \mathrm{m}$. Conditions are the same as indicated in Figure 4. The azimuthal direction of the thermal wave over the free surface due to the HTW is counterclockwise for all images. Ma is evaluated by applying $H$ for the characteristic length $L$. ( Figure 5 in Gotoda et al. [13]).

\subsubsection{Particle Behaviours}

When one pays their attention to a single particle motion, one finds its characteristics to form the PAS. In addition to the basic turnover motion in the $r-z$ plane due to the thermocapillary-driven convection, the particle exhibits azimuthal motion in the oscillatory convection [8]; the net azimuthal direction of the particle motion is opposite to that of the PAS itself. When the particle forms the PAS, the turnover motion itself varies as Ma; Gotoda et al. [13] indicated the variation of the particle trajectory from (i) strictly periodic to (ii-iii) quasi-periodic and (iv) period doubled by varying Ma (Figure 6a). Such variation is clearly illustrated by monitoring the particle position in $r$ (frame (b)) and its Fourier spectrum (frame (c)). When attention is paid to the absolute minimum of the particle position in $r$ (corresponding to $R_{\text {PAS }}$ as indicated in Figure 4), the variation of the minimum position of the particle in $r$ depends on Ma. In the case of (i), the minimum position is almost constant. By increasing Ma for (ii) and (iii), it exhibits periodic modulations. By further increasing Ma to realize the period-doubled PAS [55], the minimum position of the travelling particle in $r$ exhibits a large oscillation, showing alternative values of 0.7 and $0.8 \mathrm{~mm}$ each time in this case, as the particles penetrate to the deepest position in the 
liquid bridge. One finds a fundamental frequency $f_{0}^{(\mathrm{p})}=2.4 \mathrm{~Hz}$ and its subharmonics $f_{0}^{(\mathrm{p})} / 2=1.2 \mathrm{~Hz}$ (the frame (c)-(iv)) for the turnover motion of the particle; this subharmonic frequency corresponds to the period-doubled trajectory of the PAS in the rotating frame of reference. It must be emphasized that the oscillatory convection itself is strictly periodic and not modulated under these conditions, which was also indicated by Toyama et al. [11] under Ma for SL1- and SL2-PASs, and even under slightly higher Ma with no stable PASs. Through the tracking of a single particle forming the PAS, the frequency ratio between the particle turnover motion $f_{0}^{(\mathrm{p})}$ and the $\operatorname{HTW} f_{0}^{(\mathrm{HTW})}$ remains almost constant (about 1.6 in this series of the experiments) under the condition where the PAS is fully formed; the ratio is independent of Ma.
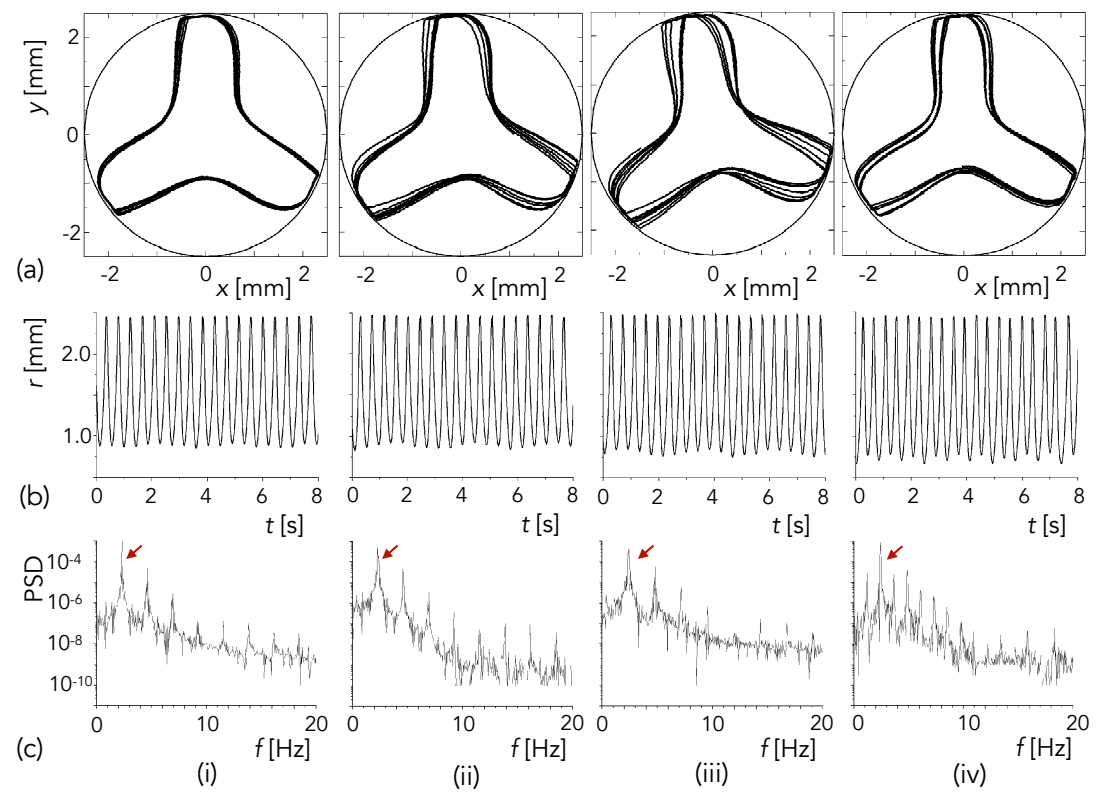

(ii)

(iii)

(iv)

Figure 6. (a) Reconstructed SL1-PAS configurations in a rotating frame of reference by tracking a single particle forming PAS, (b) time series of particle radial positions, and (c) its power spectral density (PSD) for Ma of (i) $3.3 \times 10^{4}$, (ii) $3.7 \times 10^{4}$, (iii) $4.2 \times 10^{4}$, and (iv) $4.6 \times 10^{4}$, respectively. Conditions of the liquid bridge are the same as indicated in Figure 4 . The particle diameter is $15 \mu \mathrm{m}$. Arrows in row (c) indicate the fundamental frequency of the particle turnover motion $f_{0}^{(\mathrm{p})}$. Ma is evaluated by applying $H$ for the characteristic length $L$. (Figure 9 in Gotoda et al. [13]).

In order to depict the particles' trajectory to form the PAS, one can monitor the Poincaré section. Figure 7 illustrates some example of the Poincaré section at $z \sim H / 2$. When one tracks a single particle forming the PAS, the particle passes several fixed areas in the $r-\theta$ plane. In the case of the PAS of $m=3$, one finds three pairs of the area; a pair consists of the area locating near the free surface (" $\mathrm{A}$ " in the frame) and near the liquid-bridge centre $($ " $B$ "). The area " $\mathrm{A}$ " near the free surface corresponds to the trajectory near the tip of the PAS blade passing the plane downward, and the area " $\mathrm{B}$ " near the centre corresponds to the trajectory where the particle follows the return flow inside the liquid bridge from the region near the cold disk toward the hot disk. One finds finite sizes of the areas. Note that these experimental results were obtained by employing rather big particles $\left(d_{\mathrm{p}}=30 \mu \mathrm{m}\right)$ and a light sheet of finite thickness. One could measure not only the size but also their shape in the Poincaré section, if one employed finer particles with finer resolution of the observation system, in order to compare with those of the KAM tori [58] .

Through such observation, one can find the particle departing from a certain trajectory to another (see Figure 8); the top frame illustrates an example of the Poincaré section detected at $z=0.81 \pm 0.09 \mathrm{~mm}$ under $\left.\mathrm{Ma}\right|_{L=H}=5.2 \times 10^{4}$ (the same as row (c) in Figure 7 but in a different experimental run). Frames (a)-(c) indicate the sections obtained in the same 
experimental run to track a single particle under the same condition but in different successive periods. Frame (d) illustrates all the data obtained in a single experimental run for $73.2 \mathrm{~s}$; that is, the sum of (a) to (c) corresponds to the original section shown as frame (d). From these successive sections, one observes that this particle does not stay to settle at a certain structure, but switches among specific structures. In this case, the particle (a) stays on the core first, then (b) migrates to stay for a while on a structure wrapping the core, and then (c) migrates to finally settle on the PAS. Each structure resembles the KAM torus realized in the thermocapillary-driven convection in the half-zone liquid bridge; the structure known as the toroidal core, the structure wrapping the toroidal core, and the PAS of $m=3$ resembles $\mathrm{T}_{\text {core }}, \mathrm{T}_{3}^{9}$, and $\mathrm{T}_{3}^{3}$ [61], respectively. The middle and bottom frames of the figure illustrate the corresponding temporal variations of the $r$ - and $\theta$-positions of a particle on the Poincare section, respectively. In the variation of the $r$-position, the corresponding KAM torus is indicated; section (a) exhibits the paths of the particle on the core, that is, the particle is attracted by $\mathrm{T}_{\text {core }}$ first. Then, the particle switches to the attractor $\mathrm{T}_{3}^{9}$ in section (b). This torus, however, does not keep attracting the particle; one finds that the particle migrates between the attractors $\mathrm{T}_{3}^{9}$ and $\mathrm{T}_{\text {core. }}$. Finally, in this case, the particle is attracted to $\mathrm{T}_{3}^{3}$ to keep forming the PAS (the section (c)). This scenario of the particle migration is not thus far predictable; each torus becomes unstable and they keep attracting particle under high Ma. It was indicated that the particle would not be able to stay for a long period especially on the core, which might reflect that the torus $\mathrm{T}_{\text {core }}$ in the high-Pr liquid bridge becomes weakly chaotic [20]. Further research is needed to describe the attractivity of each structure of KAM tori and the mechanism on the interaction between the particles and the KAM tori.

(a)

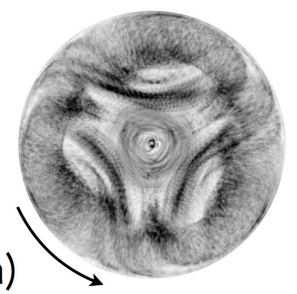

(b)

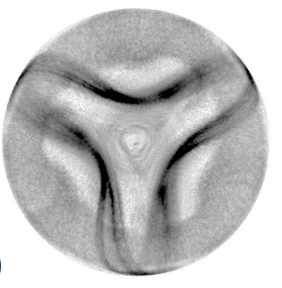

(c)

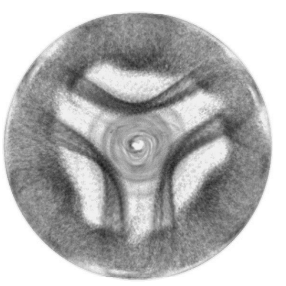

(i)
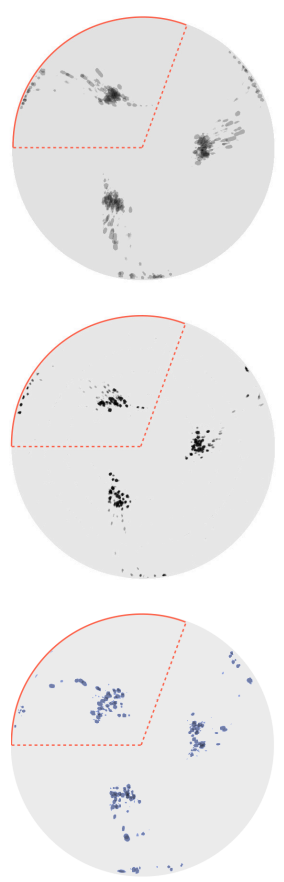

(ii)
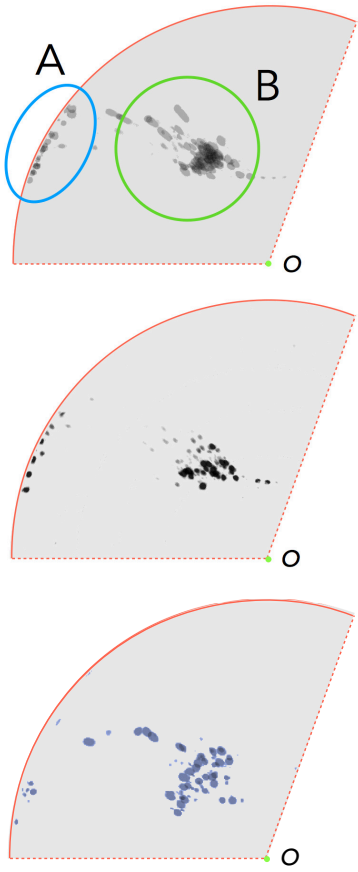

(iii)

Figure 7. PASs observed through the top rod in a rotating frame of reference under $\mathrm{Ma}=(\mathbf{a})$ $4.1 \times 10^{4}$, (b) $4.7 \times 10^{4}$, and (c) $5.2 \times 10^{4}$ in a liquid bridge of $\operatorname{Pr}=28.5, \Gamma=0.68(R=2.5 \mathrm{~mm})$, and $V / V_{0}=1.0$ with suspended particles $30 \mu \mathrm{m}$ in diameter: Columns (i,ii) indicate the projected images, and Poincaré sections at midheight of the liquid bridge, respectively. Images for column (i) are obtained by by integrating 500 frames (for about $8.3 \mathrm{~s}$ ). Images for (ii)-(a) and -(b) are obtained by integrating 3900 frames (for almost $65 \mathrm{~s}$ ), and -(c) 2340 frames (for almost $39 \mathrm{~s}$ ). Column (iii) shows a zoomed view of the $1 / 3=1 / m_{0}$ region of the image in (ii). The fundamental frequencies $f_{0}^{(\mathrm{HTW})}$ are (a) $1.41 \mathrm{~Hz},(\mathbf{b}) 1.42 \mathrm{~Hz}$, and (c) $1.44 \mathrm{~Hz}$. The rotating direction of the HTW in this figure is counter-clockwise in the laboratory frame. Ma is evaluated by applying $H$ for the characteristic length L. ( Figure 2 in Yamaguchi et al. [12]). 

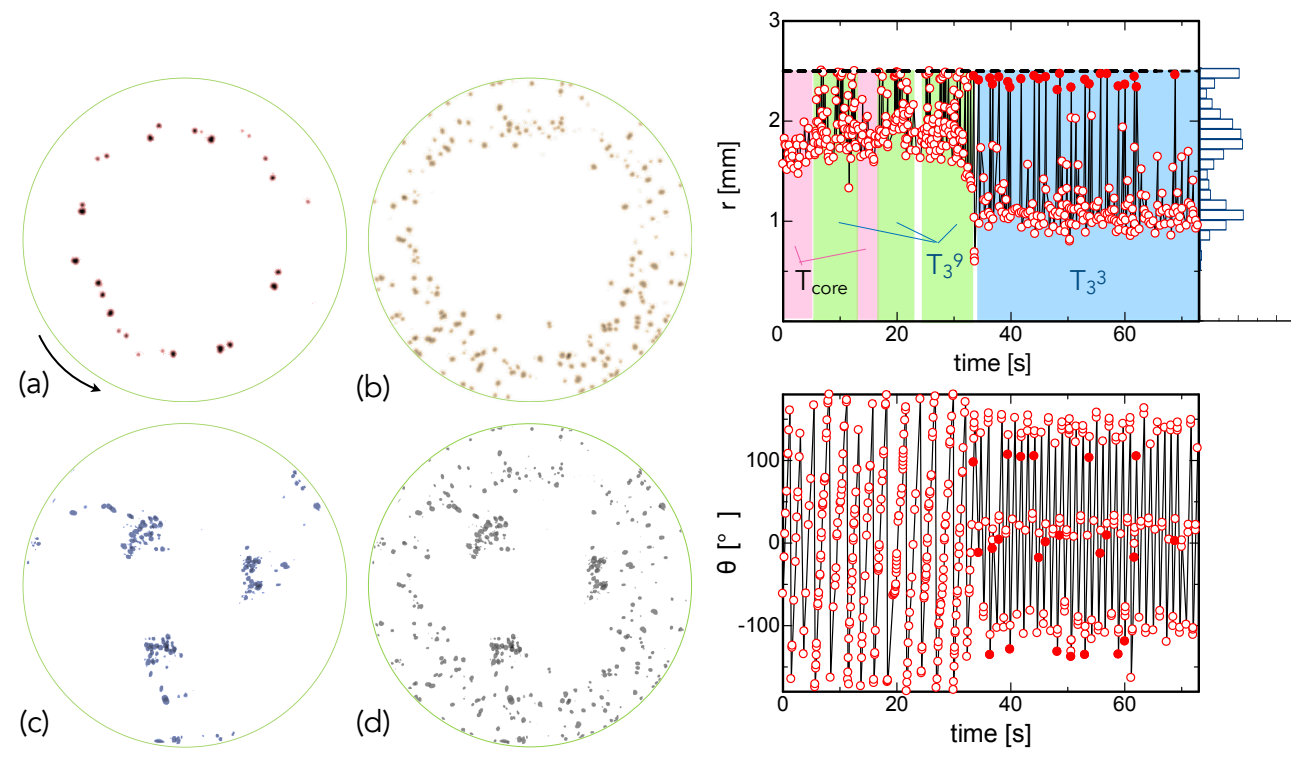

Figure 8. (left) Poincaré section at the midheight of the liquid bridge obtained by integrating (a) $0 \leq t[\mathrm{~s}] \leq 6.1$, (b) $6.1 \leq t \leq 33.4$, (c) $33.4 \leq t \leq 73.2$ and (d) total images of the section for $73.2 \mathrm{~s}$ detected at $z=0.81 \pm 0.09 \mathrm{~mm}$ under Ma $=5.2 \times 10^{4}$ (same as row (c) in Figure 7 but in a different experimental run). (Middle) and (right) corresponding temporal variations of $r$ - and $\theta$-positions of a particle on the Poincaré section, respectively. The histogram on the right of the top graph illustrates the particle number density measured with a constant interval $\Delta r=0.1 \mathrm{~mm}$ in the observation period. The direction of the travelling-wave-type oscillation is counter-clockwise in the laboratory frame. The conditions are the same as those in Figure 7. (Figure 4 in Yamaguchi et al. [12]).

It is of great importance and indispensable to detect the three-dimensional behaviour of the particles in order to understand the mechanism of PAS formation and the correlation with the KAM tori. It is, however, quite difficult especially under normal gravity conditions because of the small size of the liquid bridge with the deformed free surface. The timedependent deformation of the free surface in the oscillatory convection prevents the precise measurement of the particles with the visible light through the free surface. In such a sense, microgravity conditions are an ideal environment because one can employ larger liquid bridges [21,42-50,63-65]. Under normal gravity, some efforts have been made to realize three-dimensional measurements of the particles inside the liquid bridge of $\mathcal{O}\left(10^{-3} \mathrm{~m}\right)$ through the transparent top rod $[60,62,66]$. Oba et al. [14] realized the three-dimensional reconstruction of the particles' position as a function of time by applying 3-D PTV with a classical algorithm (see Figure 9): frames (a) and (b) illustrate the reconstructed trajectories of the particles in the bird's-eye view and the top views, respectively, and frame (c) shows the distributions of all trajectories in the $r-\phi$ (top) and the $z-\phi$ (bottom) planes. The figures in frames (a) and (b) consist of the trajectories of the particles on the PAS (14 trajectories in blue), on the toroidal core (16 in red), and on the structure wrapping the core ( 3 in green). Note that the trajectories were obtained in the $1 / 3$ region of the liquid bridge in the azimuthal direction by the experiments, and the same results are plotted repeatedly with a phase difference of $\pm 2 \pi / 3$ in the rest region; this process is based on the three-fold rotational symmetric structure of the flow field. Because of the high frequency of the particle motions in the small-size liquid bridge, Oba et al. [14] employed synchronized high-speed cameras. One can track the motion of the particles forming the various coherent structures as a function of time. 

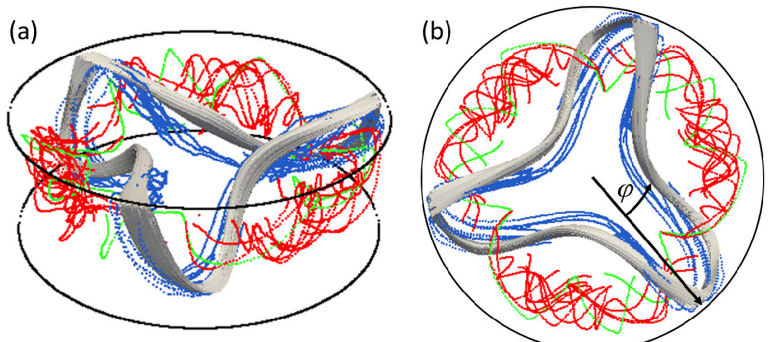

(c)

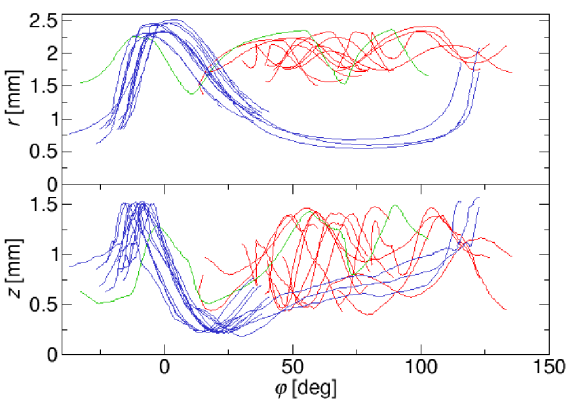

Figure 9. Reconstructed trajectories of particles in (a) bird's-eye view and (b) top view, respectively, in the liquid bridge of $\operatorname{Pr}=28.6, \Gamma=0.68(R=2.5 \mathrm{~mm})$, and $V / V_{0}=1.0$ with suspended particles of $30 \mu \mathrm{m}$ in diameter. The figures consist of the trajectories of the particles on the PAS (14 trajectories in blue), on the core (16 in red) and on the structure wrapping the core ( 3 in green). The direction of HTW is clockwise, and the net direction of the particles on the PAS is counter-clockwise (in positive $\phi$ direction) in the laboratory frame. Bundles of pathlines which form the PAS obtained by the numerical simulation [67] are also drawn in grey. Frame (c): distributions of all trajectories in the $r-\phi$ (top) and the $z-\phi$ (bottom) planes. (Figure 9 in Oba et al. [14]).

When one obtains the three-dimensional behaviour of the particles, their motions at designated area can be monitored (see Figure 10). It was found that the particles form various structures which resemble various $K A M$ tori such as $\mathrm{T}_{3}^{3}, \mathrm{~T}_{3}^{9}$, and $\mathrm{T}_{\text {core }}$ as indicated by the model flow [58]. As aforementioned, one needs finer tracking with smaller particles in order to make a comprehensive comparison between the KAM tori and the coherent structures in more detail.
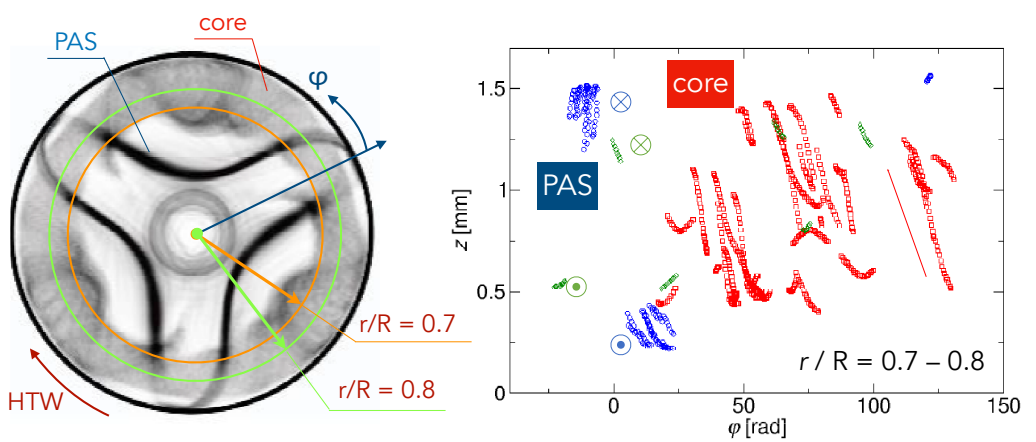

Figure 10. (left) Coherent structure under the same condition as shown in Figure 9, and (right) spatial distributions of paths in the $z-\phi$ space in $0.7 \leq r / R<0.8$. In the right frame, the particles attracted to $\mathrm{T}_{3}^{3}, \mathrm{~T}_{\text {core }}$ and $\mathrm{T}_{3}^{9}$ are drawn in blue, red and green, respectively. The arrow indicates the direction of motion of the particles concerned. The direction in $r$ of the particle motions is also indicated; $\odot$ indicates the motion toward the free surface (or in positive $r$ direction), and $\otimes$ that toward the centre axis of the liquid bridge (or in negative $r$ direction).

\subsubsection{On-Going Topics}

The azimuthal wave number of the oscillatory convection depends on the shape of the liquid bridge, especially on the aspect ratio $\Gamma$. Because of the gravity effect as well as 
the Rayleigh limit, the main target of the investigation has been the oscillatory convection with $2 \leq m \leq 4[8,9]$. Note that the experiments with short liquid bridges for larger $m$ $(m \geq 5)$ [68] involve the critical problem of the evaporation; one has to increase $\Delta T$ to realize higher Ma despite smaller characteristic length $L$. Therefore, it is rather difficult to find any knowledge accumulated from the experimental approaches to the PAS of $m=1$ and $m \geq 5$. As for the PAS of $m=1$, a small amount of research from terrestrial experiments can be found: Sasaki et al. [69] and Schwabe et al. [9] examined the PAS of $m=1$ in the liquid bridge of moderate Pr. Despite the fact that Schwabe et al. [9] indicated that the existing range of the PAS of $m=1$ against $\Gamma$ and Ma is much narrower than those of the PAS of $2 \leq m \leq 4$, it was found that two types of PAS of $m=1$ exist by varying Ma. It must be noted that the PAS of $m \geq 2$ also exhibits two types by increasing Ma (SL1- and SL2-PASs [8] as introduced), but the variation of the PAS of $m=1$ is different from those: when one observes from above, the particles form the closed path with a spiral structure inside the liquid bridge for the SL-PAS under lower Ma [69]. Such a spiral structure corresponds to the helical motion following the return flow in the central region. As for the SL-PAS under higher Ma, on the other hand, the particles form the closed path without such a spiral structure. That is, this type of PAS realized at higher Ma exhibits a simpler structure. It seems opposite to the correlation for the SL1- and SL2-PASs of $m \geq 2$ against Ma. Schwabe et al. [9] also realized the SL-PAS of $m=1$ with a spiral structure in the central region of the liquid bridge. The author's group at Tokyo University of Science recently realized the SL-PAS with a spiral structure in the liquid bridge of $\operatorname{Pr}=28.6$, and succeeded in the reconstruction in the rotating frame of reference (see Figure 11a) [70]. This PAS of $m=1$ is realized under Ma $\left.\right|_{L=H}=1.86 \times 10^{4}$ or $\Delta T=20 \mathrm{~K}$ in the liquid bridge of $\Gamma=2.0(R=0.75 \mathrm{~mm})$ and $V / V_{0}=0.8$. The induced oscillatory convection seems to correspond to the type of hydrothermal wave (HTW) (b) indicated by the linear stability analysis [71] by judging the spatial distribution of the temperature deviation over the free surface (frame (b)). Recently the SL-PAS of $m=1$ with a spiral structure was finely reproduced in the liquid bridge of $\operatorname{Pr}=8$ by Capobianchi and Lappa [72] via the numerical simulation. They indicated the correlation between the coherent structure and the KAM torus. It must be noticed, however, that they reproduced the coherent structure only by the particle lighter than the test liquid, or, $\varrho=\rho_{\mathrm{p}} / \rho_{1}<1$. The terrestrial experiments $[9,69,70]$ have revealed that the particles of $\varrho>1$ realize the coherent structure of $m=1$ as those of $m \geq 2[8,9,13,14,59,60,62]$. As for the SL-PAS of $m=1$ without a spiral structure, it was also numerically reproduced by Barmak et al. [73,74]. They illustrated that the attracting orbit exhibits multiple revolutions. Knowledge on the PAS of $m=1$ has gradually accumulated, but further research is surely needed via experimental approaches for comprehensive understanding of the coherent structures of $m=1$ in tall liquid bridges.
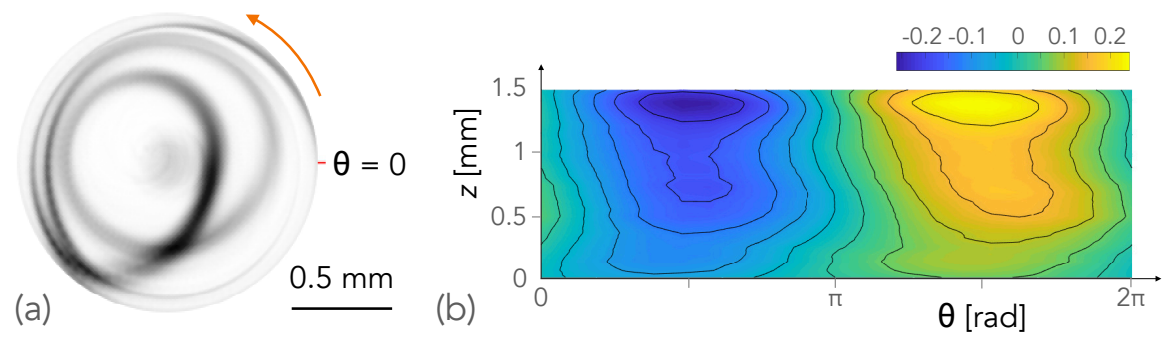

Figure 11. (a) Coherent structure in the rotating frame of reference observed through a hot disk and (b) temperature-deviation distribution over free surface from a terrestrial experiment with a liquid bridge of $\Gamma=2.0(R=0.75 \mathrm{~mm})$ and $V / V_{0}=0.8$ under Ma $\left.\right|_{L=H}=1.86 \times 10^{4}$. The image of (a) the coherent structure is drawn by integrating for 10 fundamental periods or $3.8 \mathrm{~s}$, and the temperature deviation in (b) is obtained by averaging the images for 65 fundamental periods or $24.7 \mathrm{~s}$. The arrow in the row (a) indicates the direction of the travelling wave. 


\title{
4. Concluding Remarks
}

Coherent structures by particles suspended in half-zone thermocapillary liquid bridges through experimental approaches were introduced in this article. After Schwabe et al. [1] found this unique phenomenon called particle accumulation structure (PAS), general knowledge on the shape, the occurring conditions, and their formation processes has accumulated. By focusing on the spatial-temporal behaviour of the particles forming the PAS of the azimuthal wave number $m=3$, a correlation between the particle behaviour and the ordered flow structures known as the Kolmogorov-Arnold-Moser tori was illustrated as functions of the intensity of the thermocapillary effect and the particle size. Recent works on the PAS of $m=1$, through the experimental and numerical approaches, were briefly introduced. Knowledge accumulated via ground-based research on this unique phenomenon would lead to future research including microgravity experiments on the International Space Station (ISS) by the project "Japanese European Research Experiments on Marangoni Instability (JEREMI)" [22,23].

Funding: The experimental research on the PAS of $m=1$ through terrestrial experiments [70] were supported by the Japan Society for the Promotion of Science (JSPS) through Challenging Research (Exploratory) (project number: 20K20977).

Institutional Review Board Statement: Not applicable.

Informed Consent Statement: Not applicable.

Acknowledgments: The author acknowledges Dietrich Schwabe, the professor emeritus of JustusLiebig-Universität Gießen, Valentina Shevtsova, Denis Melnikov, Aliaksandr Mialdun, and Yury Gaponenko (Université Libre de Bruxelles), Hendrik C. Kuhlmann, Thomas Lemée, and Francesco Romanò (TU Wien), Marcello Lappa (University of Strathclyde), Koichi Nishino (Yokohama National University), Taishi Yano (Kanagawa University), Hiroshi Kawamura (professor emeritus) and Shiho Tanaka who belonged to Tokyo University of Science, for fruitful discussion. The author also acknowledges ex- and current graduate and undergraduate students belonging to the Interfacial Thermo-Fluid Dynamics Lab at Tokyo University of Science; all of experimental results introduced in this article owe to their invaluable contributions.

Conflicts of Interest: The author declares no conflict of interest.

\author{
Abbreviations \\ The following abbreviations are used in this manuscript: \\ HTW Hydrothermal wave \\ JEREMI Japanese European Research Experiments on Marangoni Instability \\ PAS Particle accumulation structure
}

\section{References and Notes}

1. Schwabe, D.; Hintz, P.; Frank, S. New features of thermocapillary convection in floating zones revealed by tracer particle accumulation structure (PAS). Microgravity Sci. Technol. 1996, 9, 163-168.

2. Preisser, F.; Schwabe, D.; Scharmann, A. Steady and oscillatory thermocapillary convection in liquid columns with free cylindrical surface. J. Fluid Mech. 1983, 126, 545-567. [CrossRef]

3. Wanschura, M.; Shevtsova, V.M.; Kuhlmann, H.C.; Rath, H.J. Convective instability mechanisms in thermocapillary liquid bridges. Phys. Fluids 1995, 7, 912-925. [CrossRef]

4. Leypoldt, J.; Kuhlmann, H.C.; Rath, H.J. Three-dimensional numerical simulation of thermocapillary flows in cylindrical liquid bridges. J. Fluid Mech. 2000, 414, 285-314. [CrossRef]

5. Ueno, I.; Tanaka, S.; Kawamura, H. Oscillatory and chaotic thermocapillary convection in a half-zone liquid bridge. Phys. Fluids 2003, 15, 408-416. [CrossRef]

6. Xu, J.J.; Davis, S.H. Convective thermocapillary instabilities in liquid bridges. Phys. Fluids 1984, 27, 1102-1107. [CrossRef]

7. Ogasawara, T.; Motegi, K.; Hori, T.; Ueno, I. Secondary instability induced by thermocapillary effect in half-zone liquid bridge of high Prandtl number fluid. Mech. Eng. Lett. 2019, 5, 1900014. [CrossRef]

8. Tanaka, S.; Kawamura, H.; Ueno, I.; Schwabe, D. Flow structure and dynamic particle accumulation in thermocapillary convection in a liquid bridge. Phys. Fluids 2006, 18, 067103. [CrossRef] 
9. Schwabe, D.; Mizev, A.I.; Udhayasankar, M.; Tanaka, S. Formation of dynamic particle accumulation structures in oscillatory thermocapillary flow in liquid bridges. Phys. Fluids 2007, 19, 072102. [CrossRef]

10. Yano, T.; Maruyama, K.; Matsunaga, T.; Nishino, K. Effect of ambient gas flow on the instability of Marangoni convection in liquid bridges of various volume ratios. Int. J. Heat Mass Transf. 2016, 99, 182-191. [CrossRef]

11. Toyama, A.; Gotoda, M.; Kaneko, T.; Ueno, I. Existence conditions and formation process of second type of spiral loop particle accumulation structure (SL-2 PAS) in half-zone liquid bridge. Microgravity Sci. Technol. 2017, 29, 263-274. [CrossRef]

12. Yamaguchi, K.; Hori, T.; Ueno, I. Long-term behaviors of a single particle forming a coherent structure in thermocapillary-driven convection in half-zone liquid bridge of high Prandtl-number fluid. Int. J. Microgravity Sci. Appl. 2019, 36, 360203.

13. Gotoda, M.; Toyama, A.; Ishimura, M.; Sano, T.; Suzuki, M.; Kaneko, T.; Ueno, I. Experimental study of coherent structures of finite-size particles in thermocapillary liquid bridges. Phys. Rev. Fluids 2019, 4, 094301. [CrossRef]

14. Oba, T.; Toyama, A.; Hori, T.; Ueno, I. Experimental study on behaviors of low-Stokes number particles in weakly chaotic structures induced by thermocapillary effect within a closed system with a free surface. Phys. Rev. Fluids 2019, 4, 104002. [CrossRef]

15. Takatsuka, M.; Tanaka, S.; Ueno, I.; Kawamura, H. Dynamic particle accumulation structure of Marangoni convection in liquid bridge-2. numerical simulation. In Proceedings of the Thermal Engineering Conference; Japan Society for Mechanical Engineers: Tokyo, Japan, 2002; pp. 307-308.

16. Seki, T.; Tanaka, S.; Kawamura, H. Numerical simulation of particle accumulatoin structure in oscillatory thermocapillary convection of a liquid bridge. In Proceedings of Thermal Engineering Conference; Japan Society for Mechanical Engineers: Tokyo, Japan, 2005; pp. 169-170.

17. Hofmann, E.; Kuhlmann, H.C. Particle accumulation on periodic orbits by repeated free surface collisions. Phys. Fluids 2011, 23, 072106. [CrossRef]

18. Melnikov, D.E.; Pushkin, D.O.; Shevtsova, V.M. Accumulation of particles in time-dependent thermocapillary flow in a liquid bridge: Modeling and experiments. Eur. Phys. J. Spec. Top. 2011, 192, 29-32. [CrossRef]

19. Lappa, M. Assessment of the role of axial vorticity in the formation of particle accumulation structures in supercritical Marangoni and hybrid thermocapillary-rotation-driven flows. Phys. Fluids 2013, 25, 012101. [CrossRef]

20. Romanò, F.; Kuhlmann, H.C. Finite-size Lagrangian coherent structures in thermocapillary liquid bridges. Phys. Rev. Fluids 2018, 3, 094302. [CrossRef]

21. Kawamura, H.; Nishino, K.; Matsumoto, S.; Ueno, I. Report on microgravity experiments of Marangoni convection aboard International Space Station. J. Heat Transf. 2012, 134, 031005. [CrossRef]

22. Shevtsova, V.; Gaponenko, Y.; Kuhlmann, H.C.; Lappa, M.; Lukasser, M.; Matsumoto, S.; Mialdun, A.; Montanero, J.M.; Nishino, K.; Ueno, I. The JEREMI-project on thermocapillary convection in liquid bridges. Part B: Overview on impact of co-axial gas flow. Fluid Dyn. Mater. Process. 2014, 10, 197-240.

23. Kuhlmann, H.C.; Lappa, M.; Melnikov, D.E.; Mukin, R.V.; Muldoon, F.H.; Pushkin, D.O.; Shevtsova, V.M.; Ueno, I. The JEREMIProject on thermocapillary convection in liquid bridge. Part A: Particle Accumulation Structures. Fluid Dyn. Mater. Process. 2014, 10, 1-10.

24. Chun, C.H.; Wuest, W. A micro-gravity simulation of the Marangoni convection. Acta Astronaut. 1978, 5, 681-686. [CrossRef]

25. Lan, C.W.; Kim, Y.J.; Kou, S. A half-zone study of Marangoni convection in floating-zone crystal growth under microgravity. J. Cryst. Growth 1990, 104, 801-808. [CrossRef]

26. Cao, Z.H.; Xie, J.C.; Tang, Z.M.; Hu, W.R. The influence of buoyancy on the onset of oscillatory convection in a half floating zone. Adv. Space Res. 1991, 11, 163-166. [CrossRef]

27. Velten, R.; Schwabe, D.; Scharmann, A. The periodic instability of thermocapillary convection in cylindrical liquid bridges. Phys. Fluids A 1991, 3, 267-279. [CrossRef]

28. Petrov, V.; Schatz, M.F.; Muehlner, K.A.; VanHook, S.J.; McCormick, W.D.; Swift, J.B.; Swinney, H.L. Nonlinear control of remote unstable states in a liquid bridge convection experiment. Phys. Rev. Lett. 1996, 77, 3779-3782. [CrossRef] [PubMed]

29. Hirata, A.; Nishizawa, S.; Sakurai, M. Experimental results of oscillatory Marangoni convection in a liquid bridge under normal gravity. J. Jpn. Soc. Microgravity Appl. 1997, 14, 122-129.

30. Hirata, A.; Sakurai, M.; Ohishi, N. Effect of gravity on Marangoni convection in a liquid bridge. J. Jpn. Soc. Microgravity Appl. 1997, 14, 130-136.

31. Shevtsova, V.M.; Mojahed, M.; Legros, J.C. The loss of stability in ground based experiments in liquid bridges. Acta Astronaut. 1999, 44, 625-634. [CrossRef]

32. Kamotani, Y.; Wang, L.; Hatta, S.; Wang, A.; Yoda, S. Free surface heat loss effect on oscillatory thermocapillary flow in liquid bridges of high Prandtl number fluids. Int. J. Heat Mass Transf. 2003, 46, 3211-3220. [CrossRef]

33. Shiomi, J.; Kudo, M.; Ueno, I.; Kawamura, H.; Amberg, G. Feedback control of oscillatory thermocapillary convection in a half-zone liquid bridge. J. Fluid Mech. 2003, 496, 193-211. [CrossRef]

34. Irikura, M.; Arakawa, Y.; Ueno, I.; Kawamura, H. Effect of ambient fluid flow upon onset of oscillatory thermocapillary convection in half-zone liquid bridge. Microgravity Sci. Technol. 2005, 16, 176-180. [CrossRef]

35. Wang, A.; Kamotani, Y.; Yoda, S. Oscillatory thermocapillary flow in liquid bridges of high Prandtl number fluid with free surface heat gain. Int. J. Heat Mass Transf. 2007, 50, 4195-4205. [CrossRef] 
36. Tiwari, S.; Nishino, K. Effect of confined and heated ambient air on onset of instability in liquid bridges of high Pr fluids. Fluid Dyn. Mater. Process. (FDMP) 2010, 6, 109-136.

37. Ueno, I.; Kawazoe, A.; Enomoto, H. Effect of ambient-gas forced flow on oscillatory thermocapillary convection of half-zone liquid bridge. Fluid Dyn. Mater. Process. (FDMP) 2010, 6, 99-108.

38. Schwabe, D.; Mizev, A.I. Particles of different density in thermocapillary liquid bridges under the action of travelling and standing hydrothermal waves. Eur. Phys. J. Spec. Top. 2011, 192, 13-27. [CrossRef]

39. Melnikov, D.E.; Pushkin, D.O.; Shevtsova, V.M. Synchronization of finite-size particles by a traveling wave in a cylindrical flow. Phys. Fluids 2013, 25, 092108. [CrossRef]

40. Melnikov, D.E.; Watanabe, T.; Matsugase, T.; Ueno, I.; Shevtsova, V. Experimental study on formation of particle accumulation structures by a thermocapillary flow in a deformable liquid column. Microgravity Sci. Technol. 2014, 26, 365-374. [CrossRef]

41. Gotoda, M.; Melnikov, D.E.; Ueno, I.; Shevtsova, V. Experimental study on dynamics of coherent structures formed by inertial solid particles in three-dimensional periodic flows. Chaos 2016, 26, 073106. [CrossRef]

42. Yano, T.; Nishino, K.; Ueno, I.; Matsumoto, S.; Kamotani, Y. Sensitivity of hydrothermal wave instability of Marangoni convection to the interfacial heat transfer in long liquid bridges of high Prandtl number fluids. Phys. Fluids 2017, 29, 044105. [CrossRef]

43. Yano, T.; Nishino, K.; Matsumoto, S.; Ueno, I.; Komiya, A.; Kamotani, Y.; Imaishi, N. Overview of "Dynamic Surf" project in Kibo-Dynamic behavior of large-scale thermocapillary liquid bridges in microgravity. Int. J. Microgravity Sci. Appl. 2018, 35, 350102.

44. Yano, T.; Nishino, K.; Matsumoto, S.; Ueno, I.; Komiya, A.; Kamotani, Y.; Imaishi, N. Report on microgravity experiments of dynamic surface deformation effects on Marangoni instability in high-Prandtl-number liquid bridges. Microgravity Sci. Technol. 2018, 30, 599-610. [CrossRef]

45. Yano, T.; Nishino, K.; Kawamura, H.; Ueno, I.; Matsumoto, S.; Ohnishi, M.; Sakurai, M. Space experiment on the instability of Marangoni convection in large liquid bridge-MEIS-4: Effect of Prandtl number. J. Phys. Conf. Ser. 2011, 327, 012029. [CrossRef]

46. Yano, T.; Nishino, K.; Kawamura, H.; Ueno, I.; Matsumoto, S.; Ohnishi, M.; Sakurai, M. 3-D PTV measurement of Marangoni convection in liquid bridge in space experiment. Exp. Fluids 2012, 53, 9-20. [CrossRef]

47. Sato, F.; Ueno, I.; Kawamura, H.; Nishino, K.; Matsumoto, S.; Ohnishi, M.; Sakurai, M. Hydrothermal wave instability in a highaspect-ratio liquid bridge of $\operatorname{Pr}>200$ On-orbit experiments in the Japanese Experiment Module 'Kibo' aboard the International Space Station. Microgravity Sci. Technol. 2013, 25, 43-58. [CrossRef]

48. Yano, T.; Nishino, K.; Kawamura, H.; Ueno, I.; Matsumoto, S. Instability and associated roll structure of Marangoni convection in high Prandtl number liquid bridge with large aspect ratio. Phys. Fluids 2015, 27, 024108. [CrossRef]

49. Nishino, K.; Yano, T.; Kawamura, H.; Matsumoto, S.; Ueno, I.; Ermakov, M.K. Instability of thermocapillary convection in long liquid bridges of high Prandtl number fluids in microgravity. J. Cryst. Growth 2015, 420, 57-63. [CrossRef]

50. Matsugase, T.; Ueno, I.; Nishino, K.; Ohnishi, M.; Sakurai, M.; Matsumoto, S.; Kawamura, H. Transition to chaotic thermocapillary convection in a half zone liquid bridge. Int. J. Heat Mass Transf. 2015, 89, 903-912. [CrossRef]

51. Pushkin, D.O.; Melnikov, D.E.; Shevtsova, V.M. Ordering of small particles in one-dimensional coherent structures by timeperiodic flows. Phys. Rev. Lett. 2011, 106, 234501. [CrossRef] [PubMed]

52. Kuhlmann, H.C.; Hofmann, E. The mechanics of particle accumulation structures in thermocapillary flows. Eur. Phys. J. Spec. Top. 2011, 192, 3-12. [CrossRef]

53. Kuhlmann, H.C.; Muldoon, F.H. Particle-accumulation structures in periodic free-surface flows: Inertia versus surface collisions. Phys. Rev. E 2012, 85, 046310. [CrossRef] [PubMed]

54. Kuhlmann, H.C.; Muldoon, F.H. On the different manifestations of particle accumulation structures (PAS) in thermocapillary flows. Eur. Phys. J. Spec. Top. 2013, 219, 59-69. [CrossRef]

55. Mukin, R.V.; Kuhlmann, H.C. Topology of hydrothermal waves in liquid bridges and dissipative structures of transported particles. Phys. Rev. E 2013, 88, 053016. [CrossRef] [PubMed]

56. Muldoon, F.H.; Kuhlmann, H.C. Origin of particle accumulation structures in liquid bridges: Particle-boundary-interactions versus inertia. Phys. Fluids 2016, 28, 073305. [CrossRef]

57. Romanò, F.; Kuhlmann, H.C.; Ishimura, M.; Ueno, I. Limit cycles for the motion of finite-size particles in axisymmetric thermocapillary flows in liquid bridges. Phys. Fluids 2017, 29, 093303. [CrossRef]

58. Muldoon, F.H.; Kuhlmann, H.C. Coherent particulate structures by boundary interaction of small particles in confined periodic flows. Phys. D Nonlinear Phenom. 2013, 253, 40-65. [CrossRef]

59. Gotoda, M.; Sano, T.; Kaneko, T.; Ueno, I. Evaluation of existence region and formation time of particle accumulation structure (PAS) in half-zone liquid bridge. Eur. Phys. J. Spec. Top. 2015, 224, 299-307. [CrossRef]

60. Abe, Y.; Ueno, I.; Kawamura, H. Dynamic particle accumulation structure due to thermocapillary effect in noncylindrical half-zone liquid bridge. Ann. N. Y. Acad. Sci. 2009, 1161, 240-245. [CrossRef] [PubMed]

61. Kuhlmann, H.C.; Mukin, R.V.; Sano, T.; Ueno, I. Structure and dynamics of particle-accumulation in thermocapillary liquid bridges. Fluid Dyn. Res. 2014, 46, 041421. [CrossRef]

62. Niigaki, Y.; Ueno, I. Formation of particle accumulation structure (PAS) in half-zone liquid bridge under an effect of thermo-fluid flow of ambient gas. Trans. JSASS (Japan Soc. Aeronaut. Space Sci. Aerosp. Technol.) 2012, 10, Ph33-Ph37. [CrossRef]

63. Kang, Q.; Wu, D.; Duan, L.; Hu, L.; Wang, J.; Zhang, P.; Hu, W. The effects of geometry and heating rate on thermocapillary convection in the liquid bridge. J. Fluid Mech. 2019, 881, 951-982. [CrossRef] 
64. Kang, Q.; Wu, D.; Duan, L.; Zhang, J.; Zhou, B.; Wang, J.; Han, Z.; Hu, L.; Hu, W. Space experimental study on wave modes under instability of thermocapillary convection in liquid bridges on Tiangong-2. Phys. Fluids 2020, 32, 034107.

65. Wang, J.; Wu, D.; Duan, L.; Kang, Q. Transition to chaos of buoyant-thermocapillary convection in large-scale liquid bridges. Microgravity Sci. Technol. 2020, 32, 217-227. [CrossRef]

66. Nishimura, M.; Ueno, I.; Nishino, K.; Kawamura, H. 3D PTV measurement of oscillatory thermocapillary convection in half-zone liquid bridge. Exp. Fluids 2005, 38, 285-290. [CrossRef]

67. Romanò, F.; Kuhlmann, H.C. Private communications.

68. Yazawa, S.; Kawamura, H. Experiment of Marangoni convection in a liquid bridge with a low to medium aspect ratio. In Proceedings of the National Heat Transfer Symposium of Japan (In Japanese), Hokkaido, Japan, 26-28 May 2010; p. SP409.

69. Sasaki, Y.; Tanaka, S.; Kawamura, H. Particle accumulation structure in thermocapillary convection of small liquid bridge. In Proceedings of the 6th Japan/China Workshop on Microgravity Sciences, Saga, Japan, 22-26 October 2005.

70. Sakata, T.; Ueno, I. The University of Tokyo, Tokyo, Japan, private communications.

71. Fujimoto, S.; Ogasawara, T.; Ota, A.; Motegi, K.; Ueno, I. Effect of heat loss on hydrothermal wave instability in half-zone liquid bridges of high Prandtl number fluid. Int. J. Microgravity Sci. Appl. 2019, 36, 360204.

72. Capobianchi, P.; Lappa, M. On the influence of gravity on particle accumulation structures in high aspect-ratio liquid bridges. J. Fluid Mech. 2021, 908, A29. [CrossRef]

73. Barmak, I.; Romanò, F.; Kuhlmann, H.C. Particle accumulation in high-Prandtl-number liquid bridges. Proc. Appl. Math. Mech. 2019, 19, e201900058. [CrossRef]

74. Barmak, I.; Romanò, F.; Kannan, P.K.; Kuhlmann, H.C. Coherent particle structures in high-Prandtl-number liquid bridges. Microgravity Sci. Technol. 2021, 33, 19. [CrossRef] 